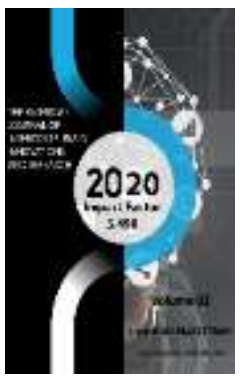

Journal Website: http://usajournalshub.c om/index,php/tajiir

Copyright: Original content from this work may be used under the terms of the creative commons attributes 4.0 licence.

\section{Obtaining Ethyl Acetate Based On Ether-Aldehyde Fraction And Acetic Acid}

\author{
Siddiqova Gulchehra Abdujalolovna \\ Assistant, Department Of Analytical, Physical And Colloid Chemistry, Tashkent Institute of \\ Chemical Technology, Tashkent, Uzbekistan \\ Musulmonov Noryigit Hasanovich \\ Candidate Of Technical Sciences, Associate Professor, Department Of Polymer Chemistry And \\ Chemical Technology, Samarkand State University, Samarkand, Uzbekistan \\ Siddiqov Abdujalol Siddiqovich \\ Doctor Of Chemical Sciences, Professor, Department Of Analytical, Physical And Colloid \\ Chemistry, Tashkent Institute Of Chemical Technology, Tashkent, Uzbekistan \\ Ikromov Abduvahob Ikromovich \\ Doctor Of Technical Sciences, Professor, Department Of Organic Chemistry And Technology \\ Of Heavy Organic Synthesis, Tashkent Institute Of Chemistry And Theology, Tashkent, \\ Uzbekistan
}

\title{
ABSTRACT
}

The article conducts systematic research on the processing of the ether-aldehyde fraction of the biochemical enterprises of the republic and the use of the purified ether-aldehyde fraction for the production of ethyl acetate. A detailed critical analysis of scientific, technical and patent literature in the field of production and use of esters and, in particular, ethyl acetate was carried out. Investigated the chemical composition of the ether-aldehyde fraction - the waste of the distilleries of the Republic. The optimal technological parameters for the purification of the ether-aldehyde fraction have been determined.

\section{KEYWORDS}

Acetic acid, energy-resource-saving technology, esterification mixture, production of ethyl acetate, production of ethyl acetate, purified ether-aldehyde fraction for ethyl acetate production.

\section{INTRODUCTION}

The esterification reactions can be carried out in liquid or vapour phase. In the liquid phase, the esterification reaction is carried out in a tray column, from the bottom of which it is heated. The esterifying mixture and sulfuric acid are placed in the column. During esterification in the vapour phase, vapours of acid and alcohol, heated to $280-300{ }^{\circ} \mathrm{C}$, are passed over a solid catalyst ( $\mathrm{ThO}_{2}, \mathrm{TiO}_{2}$, etc.). 
The yield of ester in liquid and vapour phases was $95 \%[1-4]$.

The optimal condition for the esterification reaction is one of the components must be taken in excess and the immediate removal of the product from the reaction zone using an acid or alkali [5-8]. Obtaining ethyl acetate by this method has the following disadvantages:

- Low ethyl acetate yield (average 62\%);

- Discontinuous process;

- Very aggressive substances are used that contribute to the corrosion of the installation (sulfuric and acetic acids) and waste is generated in large quantities;

- High consumption of sulfuric acid (for $1 \mathrm{~mol}$ of acetic acid, $0.46 \mathrm{~mol}$ of sulfuric acid);

- The process is carried out at high pressure (77.3 atm) and temperature $\left(150^{\circ} \mathrm{C}\right)$ [17-24].

Esters are used in the paint and varnish industry as a solvent. They are also good plasticizers and are intermediates in organic synthesis.

\section{MATERIALS AND METHODS}

Ethyl acetate is found in essential oils of Japanese mint, in many fruits and berries, and has a strong essential-fruity odor. It is used in large quantities in the confectionery industry (to obtain food aromatic essences) [6-11]. Ethyl acetate is an identical natural food flavour. It is used as a solvent in the production of varnishes, artificial leather, silk, is used to dissolve fats, artificial resins, is used as an extractant in the extraction of acetic acid from solutions, in the photochemical industry, etc. [12-14]. The maximum concentration limit for ethyl acetate is $200 \mathrm{mg} / \mathrm{m} 3$ [14-19].
Ethyl acetate is industrially obtained by heating dried ethyl alcohol with acetic acid in the presence of sulfuric acid (2-3\% of acetic acid) at a temperature of $110-115{ }^{\circ} \mathrm{C}$ for 2 hours [19-20]. Known methods for producing ethyl acetate by heating the acetic-calcium salt and sulfuric acid with ethyl alcohol, the action of acetaldehyde on aluminium ethylate in the presence of chlorides or a small amount of water (Tishchenko's method) [15-16], dehydrogenation of ethanol in the presence of copper-zinc catalysts at a temperature of 200$300{ }^{\circ} \mathrm{C}$ and a pressure of 0.1-2.0 MPa [16-21]. All of the above methods for producing ethyl acetate are time consuming and require heating or high pressure. Known methods for the synthesis of esters of carboxylic acids by the reaction of direct esterification under microwave irradiation [13-17].

The proposed method for producing ethyl acetate reduces the reaction time by tens of times, this saves the cost of electrical or thermal energy and, accordingly, includes the production of ethyl acetate in the field of "green" chemistry. To obtain pure ethyl acetate, it is necessary to use ethyl alcohol with a basic substance content of at least $85 \%$. Therefore, further research was aimed at purifying the ether-aldehyde fraction from accompanying impurities and obtaining a purified ether-aldehyde fraction. To purify the ether-aldehyde fraction from easily and heavily volatile impurities, two types of apparatus are used. The first type of apparatus is batch-type depuration columns. At the first stage, the ether-aldehyde fraction is purified from easily volatile impurities. At the second stage - from heavily volatile impurities. The second type of apparatus is continuous rectification columns. On the epuration column, readily volatile 
impurities are emitted, and on the rectification column, heavy volatile impurities. These processes are carried out simultaneously and continuously. To purify the ether-aldehyde fraction, a laboratory unit was assembled (Fig. 1). A flat-bottomed flask with a volume of 500 $\mathrm{ml}$ (item 2) was installed on an electric hotplate with a variable heating rate (item 1). A reflux condenser with a thin section (item 3 ) and a level gauge (item 4) is installed on the flask. A thermometer (pos. 5) and two coolers (pos. 7) combined through a tap (pos. 6) are installed on the top of the reflux condenser with a thin section. At the first stage, the aqueous solution of the ether-aldehyde fraction was purified from light boiling substances; at the second stage, the main product was isolated from the upper part of the column, heavy-boiling impurities and water remained in the flask (item 2).

The first method is time-consuming and energy-intensive, therefore it is not economically feasible. But the second method, a continuous apparatus, is compact and timesaving and energy-saving, and conducting initial research with a small amount of raw materials and establishing the main technological parameters of the processes does not require special conditions and reproduces the ongoing processes well. Studies have shown that the head fraction - the volatile components of methyl alcohol, aldehydes, ketones are released from the ether-aldehyde fraction at temperatures of 65$74{ }^{\circ} \mathrm{C}$. Starting from $75{ }^{\circ} \mathrm{C}$ to $85^{\circ} \mathrm{C}$, the main fraction is released - ethyl alcohol.

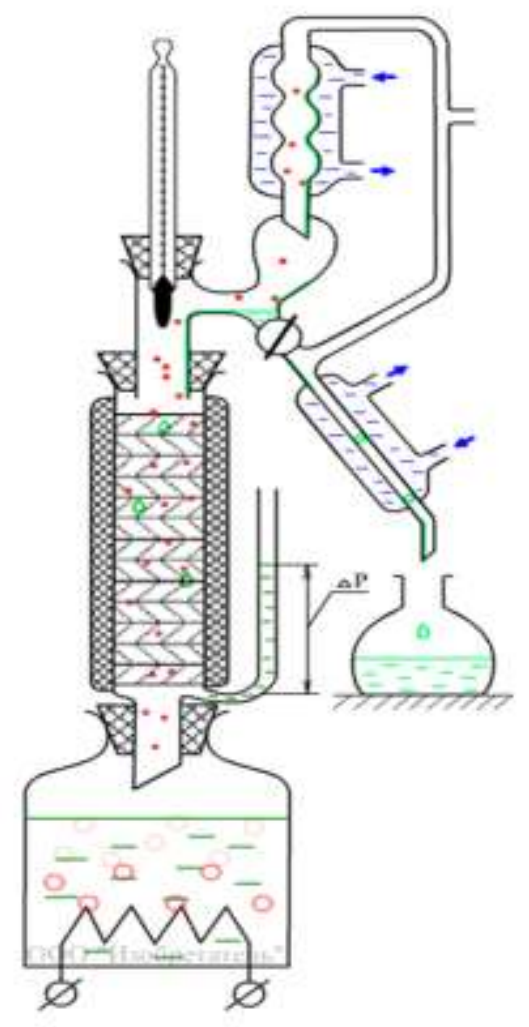

Figure 1. Apparatus for batch cleaning of the ether-aldehyde fraction.

After $85{ }^{\circ} \mathrm{C}$ - heavy fraction - acids, fusel alcohols, water. Therefore, for purification of the ether-aldehyde fraction and the isolation of ethyl alcohol, it is first of all necessary to remove the head fraction of the etheraldehyde fraction and only then to isolate the main fraction. The heavy boiling fraction remains in the flask. Based on the data obtained, an energy-resource-saving technology for the production of ethyl acetate based on the ether-aldehyde fraction and acetic acid has been developed. The developed technology consists of the following stages: separation of volatile components in an elution column, separation of ethyl alcohol in a rectification column, carrying out an esterification reaction with acetic acid in the 
presence of a catalyst - sulfuric acid, neutralization of crude ethyl acetate and bottoms with soda ash, washing with sodium sulphite solution, drying with anhydrous calcium chlorides, separation of the main product - ethyl acetate (99\%), azeotropic distillation. The dryness of the ethyl acetate production process using EAF is: washing with purified EAF, neutralization, drying and separation by azeotropic distillation.

The advantages of the developed technology for the production of ethyl acetate from EAF are as follows:

- Waste from the ethyl alcohol production industry is used as a raw material;

- The purity of the resulting ethyl acetate is 99-99.5\%.

The teaching of pure ethyl acetate from the EAF of the ethyl alcohol industry consists of the following stages:

1. Cleaning the EAF;

2. Mixing of the main components and catalyst;

3. Esterification of purified EAF and acetic acid;

4. $\quad$ Formation of ethyl acetate;

5. Neutralization of the product and still bottoms;

6. Washing with ethyl acetate;

7. Azeotropic distillation of the main product.

The etheraldehyde fraction (EAF) is diluted with water at room temperature to $35-40 \%$ of the main product (1). With the help of a pump (2), it is fed from an ethanol column (3) into a container located at a height of 1 meter (4). From the tank (4) through the rotometer (5) it is fed into the heat exchanger (6), in the back side of which there is a thermometer with a scale up to $100{ }^{\circ} \mathrm{C}$. Where it is heated to $70-75^{\circ} \mathrm{C}$ and with the help of a container filled to half with softened water (7) is sent to a disc-shaped separation column (3). The temperature of the vessel (7) fixed at the bottom of the separation column is $82-85{ }^{\circ} \mathrm{C}$. The temperature of the water flowing through the reflux condenser (10) is about $50^{\circ} \mathrm{C}$. The initial product fractions are collected in a container (11) through a condenser (9) and a reflux condenser (10) using a refrigerator (8). The eluate collected in a container (7), with a temperature of $82-85^{\circ} \mathrm{C}$, through a special valve using a container halffilled with water (13) $25 \%$ of the volume is sent to a rectification plate heated to $82-85^{\circ} \mathrm{C}$ (12). Using a cylinder (16) equipped with a refrigerator (14) and an alcohol meter, (90\%) is collected from the plates of the rectification column into a container (17).

The temperature of the lowest part of the distillation column is $100{ }^{\circ} \mathrm{C}$ (12), the temperature of the container attached to it (13) is $105^{\circ}$. From the bottom of the ratification column trays (12), water and concentrate are collected through valves into a container (13). The esterification process is carried out in the presence of a sulfuric acid catalyst, at atmospheric pressure and a temperature of 80$100^{\circ} \mathrm{C}$. For this, EAF and purified acetic acid are mixed in a ratio of 1.1: $1 \mathrm{~mol}$ and concentrated sulfuric acid $3 \%$ of the amount of the mixture. Next, the ethyl acetate raw material is washed with a $5 \%$ sodium bisulfite solution, neutralized with soda ash, dried with dry calcium chloride or sodium sulfate, then the azeotropic mixture is distilled. The result is ethyl acetate with a purity of at least $99.6 \%$, which corresponds to GOST 8991-78. The production capacity is -258 tons. The technology for the production of 
ethyl acetate from EAF has been established at JSC FARGONAAZOT on an industrial scale.

\section{CONCLUSION}

1. A detailed critical analysis of scientific, technical and patent literature in the field of production and use of esters and, in particular, ethyl acetate, has been carried out. Investigated the chemical composition of the etheraldehyde fraction - the waste of the distilleries of the Republic.

2. Systematic studies have been carried out on the processing of the etheraldehyde fraction of the biochemical plants of the Republic and the use of the purified ether-aldehyde fraction for the production of ethyl acetate. The optimal technological parameters for the purification of the ether-aldehyde fraction have been determined.

3. An energy-resource-saving technology for producing ethyl acetate based on the ester of the aldehyde fraction and acetic acid has been developed.

4. A technological scheme for processing the ether-aldehyde fraction with the production of ethyl acetate has been developed, sketches and drawings of a continuously operating installation have been prepared, the necessary equipment has been manufactured and a pilot installation has been installed.

\section{REFERENCES} N.Fayzullayev, SMT, \&
R.B.Jumanazarov.
Heterogeneous Catalytic Synthesis of
Vinylchloride by Hydrochlorination of
Acetylene. IJISET - International Journal of Innovative Science, Engineering.

2. Akmalaev, K. A., Fayzullaev, N. I., \& Karjavov, A. (2020). Joint synthesis of acetone and acetaldehyde from acetylene. Asian Journal of Multidimensional Research (AJMR), 9(8), 38-47.

3. Fayzullaev, N. I., Akmalaev, K. A., \& Karjavov, A. (2020). Catalytic Synthesis

Of Acetone From Acetylene. The American Journal of Applied sciences, 2(09), 101-109.

4. Akmalaiuly, K., Ibodullaevich, F. N., \& Rahmonovich, K. A. (2020). Joint Synthesis of Acetone And Acetaldehyde From Acetylene. The American Journal of Engineering and Technology, 2(09), 109-119.

5. Jaloliddinova, N. D., \& Sultonov, R. A. (2019). Renewable sources of energy: advantages and disadvantages. Achievements in science and education, (8-3), 49.

6. Fayzullayev, N., Akmalaiuly, K., \& Karjavov, A. (2020). Catalytic synthesis of a line by acetylene hydration. News of the National Academy of Sciences of the Republic of Kazakhstan, Series chemistry and technology, 2(440), 2330.

7. Omanov, B. S., Fayzullayev, N. I., \& Xatamova, M. S. (2019). Vinylacetate production out of acetylene. International Journal of Advanced Research in Science, Engineering and Technology, 6(12).

8. Fayzullaev, N. I., \& Sh, S. B. (2018). Catalytic aromatization of methane with non-mo-contained catalysts. 
Austrian Journal of Technical and Natural Sciences, (7-8).

9. Ugli, O. B. S., Ibodullayevich, F. N., Anorboevich, E. K., \& Sattorovna, K. M. (2020). Production of vinyl acetate from acetylene. ACADEMICIA: An International Multidisciplinary Research Journal, 10(6), 1031-1038.

10. Fayzullayev, N. I. (2019). Kinetics and mechanism of the reaction of the catalytic oxycondensation reaction of methane. Austrian Journal of Technical and Natural Sciences, (5-6).

11. Omanov, B. S., Fayzullaev, N. I., Musulmonov, N. K., Xatamova, M. S., \& Asrorov, D. A. (2020). Optimization of Vinyl Acetate Synthesis Process. International Journal of Control and Automation, 13(1), 231-238.

12. Fayzullaev, N. I., Akmalaev, K. A., Karjavov, A., Akbarov, H. I., \& Qobilov, E. (2020). Catalytic Synthesis Of Acetone And Acetaldehyde From Acetylene In Fluoride-Based Catalysts. The American Journal of Interdisciplinary Innovations and Research, 2(09), 89-100.

13. Omanov, MSX BS, \& Fayzullaev, NI (2020). Vinyl Acetate Production Technology. International Journal of Advanced Science and Technology, 29, 4923-4930.

14. Abdurakhmonova, N. K., Nazirova, R. M., \& Mirsalimova, S. R. (2020). Phosphoric-potash fertilizers based on sulfuric acid processing of phosphorite flour and potassium chloride. ACADEMICIA: An International Multidisciplinary Research Journal, 10(10), 252-255.
15. Fayzullaev, N. I., Yusupov, D., Shirinov, X. S., Korotoev, A. V., \& Umirzakov, R. R. (2002). Catalytic vaporphase hydration of acetylene and its derivatives. Chemical Industry. N, 7, 133.

16. Muradov, K. M., Fayzullayev, N. I., \& Zohidov, K. A. (2003, September). Investigation of influence of various factors to oxidative condensation of methane in C2-hydrocarbons. In Abstracts of papers of the american chemical society, (Vol. 226, pp. U258U259). 1155 16TH ST, NW, Washington, DC 20036 USA: Amer Chemical SOC.

17. Fayzullaev, N. I., Yusupov, D., Egamberdiev, R., \& Korotoev, A. V. (2000). About mechanizm of investigation of acetone in hydration of acetilene multifunctional catalist. Uzbekskii Khimicheskii Zhurnal, (6), 4042.

18. Roziqova, D. A., Sobirov, M. M., Nazirova, R. M., \& Hamdamova, S. (2020). Production of nitrogenphosphorus-potassium fertilizers based on washed hot concentrate, ammonium nitrate and potassium chloride. ACADEMICIA: An International Multidisciplinary Research Journal, 10(9), 215-220.

19. Jaloliddinova, N. D., \& Sultonov, R. A. (2019). Renewable sources of energy: advantages and disadvantages. Dostizheniya nauki i obrazovaniya, (83),

20. Kenzhebek, A., \& Fayzullaev, N. (2020). Heterogeneous-catalytic synthesis of vinyl chloride and chloroprene from acetylene. Collection of Science Works LOGOS, 120-127. 
21. Faizullaev, N. (2020). Heterogeneous-

catalytic acetylation of acetylene.

Zbírnik naukovix prats LÓGOS, 26-31. 